\section{Ueber Ernährungs- und Gewichtsverhältnisse eines fiebernden Säuglings.}

Vou

\author{
Dr. J. Lffelmann,
}

Professor der Medicin in Rostock.

(Schluss aus No. 31.)

Der Uebersichtlichkeit wegen lasse ich lier noch einmal graplisch die Aenderungen des Körpergewichts folgen, indem ich jedoch nur die uns interessirende Zeit rom 28. Norember 1878 bis zum 24. Januar 1879 berüicksichtige.
Man könnte nun auch hier wiederum den Einwurf machen, dass möglicherweise die Gewichtssteigerung zu keiner Zeit eine wabre gewesen sei. Tun, ich bin selbstrerständlich nicht in der Lage, hier einen solchen Einwurf als nichtig elweisen zu können, da es absolut unmöglich war, einen Stickstoffeinnahmeund Stickstoffausgabe - Etat aufzustellen. Da aber die Steigerung des Gewichts jedesinal mit einer Besserung des Verhaltens der Faeces zusammenfiel, so würde es doch wohl allzu skeptisch gedacht sein, wenn man eine verstärkte Aufnabme ron plastischen Substanzen ausschliessen wollte, und dies um so mehr, als das Aussehen des Kindes während der fraglichen Perioden keinerlei Halt für die Ansicht bot, als könne die Gewichtszunahme durch rermehrte Aufnalıme von Wasser bedingt gewesen sein.

Nutzbringender scheint mir eine Beantwortung der Frage, weshalb überhaupt hier keine Abnahme des Gewichts Statt hatte. Von Wichtigkeit ist in diesel Beziehung gewiss die Individualität des Kindes gewesen; denu hier hatten augenscheinlich selbst holı Fiebergrade eine riel geringere Rückwirkung auf den Gesammtorganismus, speciell auf die Verdauungsorgane, als dies sonst der Fall ist. Es giebt Individuen, welche schon bei den leichtesten Fiebergraden den Appetit einbüssen, und andere, welche noch bei mittelhohem Fieber, leidlich gern essen. Dies Kind hat selbst bei einer Temperatur

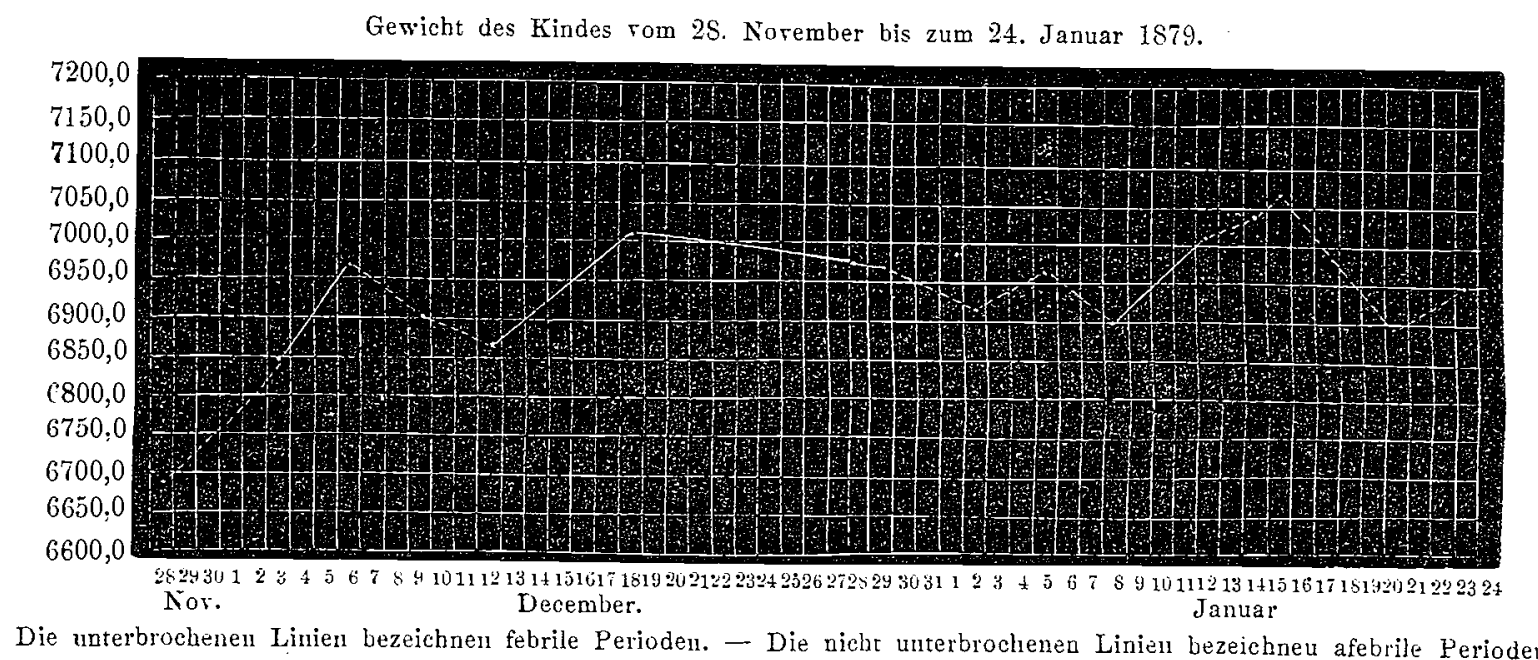

An diese Uebersicht erlaube ich mir zum Schlusse noch einige allgemeine Erörterungen anzuknüpfen. Der Fall betrifft wiederum ein an der Mutterbrust ernäbrtes Kind. Fast alle meine bisherigen Beobachtungen über Gewichtszunabme im Fieber beziehen sicl auf solche Kinder. Dies ist gerriss nicht zufällig und dürfte siclı unsclıwer daraus erklären, dass nicht blos die Muttermilch leichter rerdaulich ist, sondern auch, dass Brustkinder fast ausnahmslos weniger alterirte Verdaunngsorgane mit in die etwa eintretende fieberlafte Krankheit hineinbringen, als künstlich ernälırte. Das letztere Moment ist gewiss, von erheblichem Einfluss auf den Grad und die Dauer der durch das Fieber erzeugten Dyspepsie. Fast alle Brustkinder verliereu in febrilen Erkrankungen weniger an Gewicht, als küustlich ernälnrte unter gleichen Verhältuissen, und schon diese Thatsache weist auf die Bedeutung der er* wähnten Momente hin.

Bei meinen früheren Beobachtungen an Brustkindern war aber, wie ausdrücklich in den betr. Darstellungen berrorgehoben wurde, die Zunabme erfolgt, naclidem anfängliche diarrhöische Stühle aufhörten. Ein Gleiches liess sich auch in vorliegendem Falle bei der ersten Steigerung des Gewichts im Fieber constatiren, wie ja bereits oben ausfübrlich besprochen wurde. Bei der Zunahme des Gewichts vom 2. zum 5. Januar und rom 13. zum 17. Januar war ein gleiches Verhältniss nicht vorbanden; es gingen keine dünnen Stühle vorlıer. voll $40,0^{\circ}$ noch ziemlich guten, bei einer Temperatur ron meniger als $39,2^{\circ}$ dagegen völlig normalen Appetit gezeigt und, renn ich ron einzelnen ganz kurzen Perioden absehe, im Fieber das Genossene gut verdaut. Sodann war die Mutter, um dem Kinde nicht zu scliaden, in der Auswahl der eigenen Nahrung ausserordentlich scrupulös. Auch kann ich hinzusetzen, dass der bei Säuglingen notorisch so sehr empfindliche Magen lier durch irgend welche eingreifende Medicamente nicht lädirt worden ist. Wer da weiss, wie leicht und wie ungemein oft auf solche Weise eine febrile Dyspepsie erhöht wird, der wird auch dies letztgenannte Moment zu würdigen rerstehen. Endlich ist nicht zu rergessen, dass das Kind in den fiaglichen Perioden keine Verluste durch diarrhöische Stüble zu erleiden hatte, die bei ausserordentlich rielen fiebernden Säuglingen rom Anfange bis zur Höhe der Krankheit sich einstellen und die Gewichtsabnalıme natürlich vergrösseru. Als während der Defervescenz vom 5. bis zum 8. Januar dünnere Entleerungen erschienen, hörte alsbald die vorlierige Steig.erung des Gewichts auf, obne dass der Appetit geringer wurde.

In einer Krankheit, nämlich vom 6. bis zum 12. Dec. hat das Kind ohne Durchfälle stetig abgenommen. Der Grund lag zweifellos in dem geringeren Appetite desselben und in der schwächeren Ausnutzung des Genossenen im Darmcanal. Beide Momente reranlassten es, dass nunmelir der febrile Verbrauch, welcher noch dazu, wie man annehmen darf, stärker 
war, als in der ersten Krankheit, nicht vollständig compensirt werden konnte. -

Aus dieser Beschreibung dürfte sich in der That ergeben, dass stickstoffhaltige Nahrung auch im acuten Fieber zum Mindesten nicht allemal die Nachtheile für den betreffenden Patienten im Gefolge hat, welche man ihr vielfach zuschreibt. Denn wir latten es doch mit acuten Fieberzuständen zu thun; auch erhielt das Kind die nämliche proteinhaltige Nalırung, welche es rordem zu sich genommen hatte, und trotzdem konnte zu drei verschiedenen Malen eine Gewichtszunahme constatirt werden. Der Fall lehrt aber auch, ein wie ungemein wiclitiges Moment das Verhalten des Verdaungsrermügens während febriler Erkrankungen gegentiber der Consumption ist, welche nun einmal mit dem Fieber einhergeht. Denn dass hier noch während des letzteren eine solche Compensation des febrilen Verlustes, wie wir sie constatirt haben, stattfinden konnte, ist doch im Wesentlichen auf das gute Verdauungsvermögen des kleinen Patienten zurückzufülıren. War aber die Gewichtszunahme desselben, wie mit Bestimmtheit anzunehmen ist, eine wahre, so ist klar, dass auch im acuten Fieber eine durchaus physiologische Verwerthung der eingeflihrten und verdauten plastischen Substanzen Statt haben kann.

Es zeigt also auch dieser Fall auf's Neue, dass jener Satz, nach welchem die Zufuhr von Protein im Fieber den Organeiweisszerfall vermehren soll, zum Mindesten keine allgemeine Gtiltigkeit hat. Und dies nachzuweisen, war der Hauptzweck meiner Mittheilung.

Endlich lernen wir aus vorstehender Beobachtung, von wie hoher Bedeutung es bei fieberhaften Erkrankungen kleiner Kinder ist, wenn während derselben diarrhöische Entleerungen nach Möglichkeit eingeschränkt oder ganz ferngehalten werden.

Nachschrift. Im Laufe der letzten Woche hat das Kind auf's Neue gefiebert und zwar wiederum in Folge von Angina tonsillaris. Die Temperatursteigerung begann am 4. März und hielt bis zum lentigen Tage (9. März) an. Ibre Höhe erreichte sie am 6. März Morgens mit 39,4 $4^{\circ}$. Auch während dieser Krankheit behielt der kleine Patient seinen Appetit und zwar vollst:indig. Das Verlalten der Faeces war nicht von der Norm abweichend, insbesondere zeigten sich in ihnen keine unverdauten Coagula.

Das Gewicht, welches am 23. Februar $=6145,0$ betrug, war am 2. März $=6250,0$ und am 9. März $=6410,0$.

Also auch jetzt wiederum hatte im acuten Fieber eine noch dazu recht erhebliche Steigerung des Körpergewichts Statt gehalst, da von del Gesammtzunahme der Woche rom 2. zum 9. März $=160,0$ doch wohl nicht mehr als $50,0-60,0$ auf die fieberfreien Tage zu rechnen sind.

Rostock den 9. März 1879. 